\title{
Book Review: Biofuels from Algae: A Promising Future Fuel
}

\author{
Ravindra Prasad * \\ Environmental Studies, University of Delhi, Delhi, India
}

Keywords: biofuels, biorefineries, biodiesel, bioenergy, hydrogen production

\author{
A book review on \\ Biofuels from Algae: A Promising Future Fuel
}

Edited by Ashok Pandey, Duu-Jong Lee, Yusuf Chisti, and Carlos R. Soccol, 2013, ISBN: 978-0-44459558-4

The book entitled Biofuel from Algae, with ISBN: 978-0-444-59558-4 edited by Ashok Pandey, DuuJong Lee, Yusuf Chisti, and Carlos R Soccol, provides in-depth information on various strategies and large-scale cultivation of algal biomass with updated state-of-art information and knowledge by the internationally recognized experts and subject peers in various areas of algal biofuels.

Algae biofuel (Chisti, 2007) has been currently recognized as the alternative and clean energy source that attracted the interests of many researchers and policymakers over the globe. Biofuel and other co-products derived from microalgae have the potential for mitigating the global greenhouse gas emission, but the implication and commercial scale production of biofuel from microalgae are still a challenging task. Researchers have been working towards the genetic engineering aspects of microalgae for high biomass and lipid yield. The book provides detailed information on the various processes of algal biomass production. Moreover, the latest information and the breakthrough researches are the cynosure features of the book. Consequently, this review provides chapter-wise brief information that may be helpful for environmentalist, biotechnologist, and biochemist for their references.

Introduction of the book starts with historical review of the algal biofuel and basics of algae biofuel technology. Chapter 1 deals with the production of algal biomass using the open-pond and closed photobioreactor system and its cost effectiveness for the commercial production of biofuel. The comparative study of open-pond system and closed photobioreactor system provides the cost-effectiveness of the system. Chapter 2 details the cultivation of microalgal through the biorefinery process. It examines the phototrophic growth aspects of photobioreactor system (Carvalho et al., 2006) at the biomass productivity level; it also focuses on cost-effectiveness and at the practical platform. Chapter 3 provides the conceptual framework on the energy supply and demand gap and suggests the strategies for sustainable production of biofuel from microalgae. It also covers the molecular, physiological, and metabolic engineering aspects of the microalgae and recent research breakthroughs done in microalgal biomass and lipid productivity in the various metabolically altered strains. Chapter 4 includes the general methodology for the routine subculturing of microalgal culture maintenance. It also contains various information regarding the methodology and quantification of carbon sequestration. It also deals with the growing carbon economy and global carbon market. Chapter 5 is focused on the harvesting of microalgal biomass, which is one of the major problems of present day. It provides information related to the efficient biomass harvesting techniques. Chapter 6 is intended to understand the heterotrophic production of algal biomass and their potential use in the field of biofuels and bioproducts. The chapter also highlights the low-cost biomass production through biorefinery-based system and improvement in the per unit microalgal biomass yield through genetic engineering, advanced culture system, 
and genetically modified algal strain selection. Chapter 7 deals with the fast bio-oil production technique and properties of biodiesel. Chapter 8 gives information about cultivation system of microalgae with the high biomass production of biodiesel from microalgae with the emphasis on the biochemistry of lipid production in algae and transesterification of the produced algal oil. Carbon capture and growth of microalgae on waste water are very well explained in this chapter. Chapter 9 deals with the prospective and challenge for the production of hydrogen from microalgae. The chapter also raises the question of feasibility of biological organism for hydrogen production over the traditional hydrogen production methods. Biological hydrogen production pathways and metabolic process are the attractive features of the chapter.

Chapter 10 talks about the industry-based production of various algal products, carbon sequestration, waste water treatment, species selection, and integrated strategy used for maximizing the potential of algal biomass. Chapter 11 deals with thermochemical and hydrothermal conversion technologies of algal biomass. It also emphasizes the refinerybased approach for the economic feasibility of the biomass production. Chapter 12 focuses on the economic aspects and commercial scale production of algal biofuels based on the life-cycle energy balance. The biofuel conversion technologies such as fermentation, hydrolysis, pyrolysis, and hydrothermal liquefaction are very well documented. Chapter 13 throws light on the LCA (Life Cycle Assessment) of algal biofuel. Environmental impact assessment and energy balance provide

\section{REFERENCES}

Carvalho, A. P., Meireles, L. A., and Malcata, F. X. (2006). Microalgal reactors: a review of enclosed system designs and performances. Biotechnol. Prog. 22, 1490-1506. doi: 10.1002/bp060065r

Chisti, Y. (2007). Biodiesel from microalgae. Biotechnol Adv. 25, 294-306. doi: 10.1016/j.biotechadv.2007.02.001

Conflict of Interest Statement: The author declares that the research was conducted in the absence of any commercial or financial the guideline for improving the contribution of LCA. Chapter 14 highlights the commercial scale production of nutraceuticals (astaxanthin and beta-carotene) and also emphasizes on the minimization of low energy consumption for low value (biofuel) products. Furthermore, it reveals the production cost of various bioproducts and suggests improvement in the existing technological processes. The unit production cost of any products depends on the biomass productivity, so the chapter greatly emphasizes minimization of the biomass production cost.

Overall, this book provides detailed information on various aspects of algal biomass and biofuel production techniques. Apart from the technological information of microalgal biomass production and their conversion for biofuel, the book also deals with the economic feasibility, genetic engineering, hydrogen metabolism, and algal biorefinery-based approaches for the sustainable production of algal biofuel.

\section{AUTHOR CONTRIBUTIONS}

The author confirms being the sole contributor of this work and approved it for publication.

\section{ACKNOWLEDGMENTS}

This work is supported by financial assistance received from University Grant Commission (Govt. of India). RP is highly thankful to University Grant Commission for providing RGNF (Rajiv Gandhi National Fellowship).

relationships that could be construed as a potential conflict of interest.

Copyright (C) 2016 Prasad. This is an open-access article distributed under the terms of the Creative Commons Attribution License (CC BY). The use, distribution or reproduction in other forums is permitted, provided the original author(s) or licensor are credited and that the original publication in this journal is cited, in accordance with accepted academic practice. No use, distribution or reproduction is permitted which does not comply with these terms. 